\title{
Medical aid adapts to increasing violence
}

$\Gamma$ wo doctors were abducted and held for ransom in the Democratic Republic of Congo. Three others were gunned down at a hospital in Afghanistan by the policeman assigned to protect them. And in Guinea, eight members of an Ebola education team were killed by a mob of locals who believed that health workers were spreading the disease.

These are among the latest entries in a database of major attacks on aid workers compiled by Humanitarian Outcomes. The international think tank has reported a steady increase in attacks over the last decade from 63 incidents involving 143 victims in 2003, to a record-breaking 264 incidents involving 474 victims in 2013.

Now new patterns in the violence, particularly towards medical humanitarians, are forcing organizations to rethink their security strategies.

Médecins Sans Frontières (MSF) Canada's Executive Director Stephen Cornish, says that until recently, medical humanitarians depended on community acceptance to ensure their safety. "Even the most hardened warriors can understand that if their children are sick, or if their wives or sisters are pregnant, they should have a safe place to receive medical care."

Increasingly, however, MSF and other organizations are seeing health workers and patients as the intended targets of violence, rather than victims of collateral damage, says Cornish. He attributes this shift to a blurring of lines between military and humanitarian operations in the past decade's war on terrorism.

Cornish cites examples of armed forces using the same white land cruisers as aid groups, posing as health workers to collect information, and setting up clinics in facilities used by humanitarians to capitalize on their goodwill with locals. The upshot: communities no longer trust that aid workers are impartial.

In Pakistan, the World Health Organization (WHO) has seen fierce backlash against polio vaccinators after the United States staged a hepatitis B vaccination campaign to hunt down Osama bin Laden in 2011. Four years

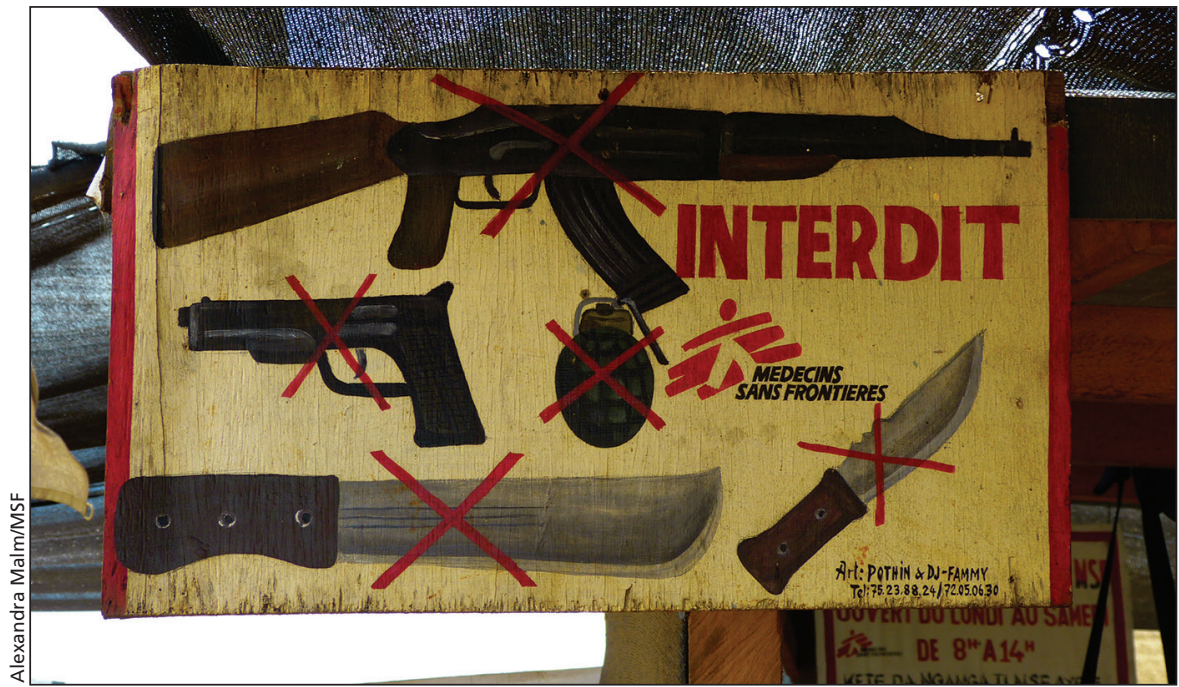

In the face of eroding community acceptance, medical humanitarians are adopting new security strategies.

later, "people are still convinced that we are spying on them or trying to locate Taliban leaders so the Americans can strike them with drones," says WHO Security Coordinator Patrick Beaufour. Militants have killed more than 60 polio workers or the police officers guarding them since 2012 .

Distrust of medical humanitarians has also proven intractable in Guinea, says Beaufour. Some people "believe that we are killing the sick in treatment centres and selling their organs to Western countries."

Traditional ways of building community acceptance, like training locals to deliver services, have failed in both these cases. Some organizations, including $\mathrm{WHO}$, have shifted to protective strategies, such as relocating services to the borders of risky areas, says Beaufour. "We conduct vaccinations when people are getting in or getting out."

Other protective strategies documented in a 2011 United Nations study include adopting a low profile, for example, by using local residences as offices, local rental cars and removing branding.

Organizations have also turned to defensive strategies, such as using armed escorts, says Beaufour. "It has to be avoided at all cost because operating like this it can make the problem with acceptance worse, but there are some areas where we know that people are ready to kill us ... and if you pull out, the local population will suffer even more."

According to Cornish, this has led some organizations to underwrite their security to the UN or a particular side of a conflict. In Afghanistan, "many organizations joined up in this political process and initially it brought more services to new areas, but when the dynamics of the conflict changed and the international actors withdrew, so did the ability of those organizations to work there," he explains. "Today, there are fewer organizations working in Afghanistan than there were in the days of the Taliban."

Experiments with new security models have also been hampered by a lack of data. Incidents involving health workers are often lumped together with attacks on other aid workers, or organizations only review incidents on a case-by-case basis, says Dr. Bruce Eshaya-Chauvin, medical advisor for the International Committee of the Red Cross' (ICRC) Health Care in Danger project.

The three-year project has brought together aid groups, governments and military in 12 workshops to draft recommendations for stemming further violence.

Both the ICRC and MSF will publish reports on incidents involving their organizations later this year. — Lauren Vogel, CMAJ

CMAJ 2015. DOI:10.1503/cmaj.109-5011 